\title{
Marketing de relacionamento em Hotéis Fazenda: um Framework a partir da experiência
}

\author{
Relationship Marketing in rural hotels: a Framework from experience
}

Marketing de Relaciones em hoteles-hacienda: un Framework a partir de la Experiencia

Iury Teixeira de Sevilha Gosling ${ }^{1}$

Daniel Carvalho de Rezende ${ }^{2}$

Marlusa de Sevilha Gosling ${ }^{3}$

Francis Marcean Resende Barros ${ }^{4}$

Rauf Rodrigues Soares

Este artigo foi recebido em 17 de JUNHO de 2019 e aprovado em 21 de JANEIRO de 2020

\begin{abstract}
Resumo: Com base na relevância das atividades turísticas, levando em conta principalmente a hospedagem, este estudo buscou analisar a experiência do turismo em hotéis fazenda na perspectiva do relacionamento entre os hóspedes e a gestão. Para isso, foram realizados seis minigrupos focais com universitários de uma instituição de ensino em Belo Horizonte/MG. Os dados foram analisados por meio da técnica de análise de conteúdo à luz de quatro categorias: qualidade, valor percebido, satisfação e cocriação. Os resultados culminaram em um framework teórico da experiência em hotéis fazenda. Na qualidade, os aspectos físicos foram considerados primordiais para uma boa experiência e revisita ou interesse em visitar. O valor percebido retratou a percepção de uma conexão com a natureza, com os familiares e grupos nos hotéis fazenda e das atividades específicas oferecidas pelos estabelecimentos. A satisfação foi especulada pela expectativa, enquanto a percepção de cocriação foi limitada a feedbacks e sugestões gerados pelos usuários. Para estudos futuros, propõe-se um teste quantitativo do modelo apresentado para a iniciativa de sua validação.
\end{abstract}

Palavras-chave: Cocriação. Marketing de relacionamento. Qualidade do serviço. Valor percebido. Satisfação.

Abstract: Based on the relevance of tourism activities, mainly in the lodging activity, this study aimed to analyze the experience of tourism in rural hotels from the perspective of the relationship between the guests and the management. Six focal mini-groups were conducted with university students from a teaching institution in Belo Horizonte / MG. The data were analyzed through the content analysis technique in light of four categories: quality, perceived value, satisfaction and co-creation. The results culminated in a theoretical framework of experience in rural hotels. In quality, the physical aspects were considered prime for a good experience and revisit or interest in visiting. The perceived value portrayed the perception of a connection with nature, with the families and groups in the farm hotels and the specific activities offered by the establishments. The satisfaction was speculated by the expectation, while the perception of cocreation was limited to feedbacks and suggestions generated by the users. For future studies, a quantitative test of the model presented for the validation initiative is proposed.

Key words: Cocreation. Relationship marketing. Service quality. Perceived value. Satisfaction.

Resumen: A partir de la relevancia de las actividades turísticas, considerando principalmente la de alojamiento, este estudio buscó analizar la experiencia del turismo en hoteles-hacienda en la perspectiva de la relación entre los huéspedes y la gestión. Para esto, se realizaron seis minigrupos focales con universitarios de una institución de enseñanza en Belo Horizonte/MG. Los datos fueron analizados por medio de la técnica de análisis de contenido a la luz de cuatro categorías: calidad, valor percibido, satisfacción y co-creación. Los resultados culminaron en un marco teórico de la experiencia en hoteles-hacienda. En la calidad, los aspectos físicos fueron considerados primordiales para una buena experiencia y revisita o interésen visitar. El valor percibido retrató la percepción de una conexión con la naturaleza, conlos familiares y grupos en los hoteles y

${ }^{1}$ Formação/curso: Bacharel em Administração, Bacharelando em Turismo, Mestre em Administração pela UFMG. Instituição: Doutorando em Administração pela UFLA. E-mail: iurygosling@gmail.com

${ }^{2}$ Formação/curso: Doutor em Ciências Sociais em Desenvolvimento, Agricultura e Sociedade pela UFRRJ. Instituição: Professor Associado da UFLA. E-mail: danielderezende@ufla.br

${ }^{3}$ Formação/curso: Doutora em Administração pela UFMG. Instituição: Professora Associada da UFMG. E-mail: marlusa@ufmg.br

${ }^{4}$ Formação/curso: Bacharel em Administração. Instituição: Mestrando em Administração pela UFMG. E-mail: francis031995@ gmail.com ${ }^{5}$ Formação/curso: Bacharel em Administração, Tecnólogo em Logística. Instituição: Mestre em Geotecnia e Transportes pela UFMG.

E-mail: raufrsoares@gmail.com 
MARKETING DE RELACIONAMENTO EM

HOTÉIS FAZENDA: UM FRAMEWORK A PARTIR

DA EXPERIÊNCIA
Iury Teixeira de Sevilha Gosling

Daniel Carvalho de Rezende

Marlusa de Sevilha Gosling

Francis Marcean Resende Barros

Rauf Rodrigues Soares

las actividades específicas ofrecidas por los establecimientos. La satisfacción fue especulada por la expectativa, mientras que la percepción de laco-creación se limitó a los comentarios y sugerencias generadas por los usuarios. Para estudios futuros, se propone una prueba cuantitativa del modelo presentado para la iniciativa de suvalidación.

Palabras Clave: Co-creación. Marketing de relaciones. Calidad del servicio. Valor percibido. Satisfacción.

\section{Introdução}

O turismo se configura como uma das mais importantes atividades que movimentam a economia em todo o mundo e é considerado como principal fonte de geração de riqueza e renda em diversos países. Dados disponibilizados pela Organização Mundial do Turismo (OMT) apontam que turismo mundial superou as expectativas de crescimento em 2017, com 1,3 bilhão de viajantes internacionais, o que significa um aumento de 7\% em relação a 2016 - o mais alto em sete anos.

No Brasil, a participação direta do turismo na economia foi de US\$ 56,8 bilhões em 2016, equivalente a 3,2\% do PIB (Brasil, 2018). Quanto ao nível de emprego no país, o setor gerou mais de 7 milhões de empregos em 2016, o que representa 7,8\% do emprego total, estes dados salientam a importância do turismo para a economia brasileira (WTTC, 2017).

Nessa seara, o Ministério do Turismo (MTUR) categorizou o turismo no Brasil em macroambientes de negócios divididos em 13 segmentos de ofertas turísticas, quais sejam, parques naturais, ecoturismo, parques temáticos, turismo de esportes, turismo náutico, turismo no espaço rural, turismo de negócios e eventos, turismo de saúde, turismo cultural - cidades históricas turísticas, turismo de aventura, turismo de estudos e intercâmbio, turismo de pesca, turismo de sol e praia, agroturismo e turismo rural na agricultura familiar (BRASIL, 2010).

Segundo o Mtur, o Turismo Rural despontou como atividade econômica em meados do século XX, primeiramente na Europa e nos Estados Unidos. No Brasil, o marco inicial da atividade se deu na década de 1980. O turismo rural compreende as atividades turísticas desenvolvidas no meio rural em modalidades definidas com base na oferta, comprometido com a produção agropecuária ao agregar valor a seus produtos e serviços, além de resgatar e promover o patrimônio cultural e natural da comunidade (BRASIL, 2010).

A partir do exposto, este artigo teve como objetivo analisar a experiência do turismo rural e a satisfação dos hóspedes, na perspectiva do relacionamento entre hóspedes e hotéis-fazenda.

O MTUR (BRASIL, 2010) classifica hotel-fazenda como aquele localizado em zona rural, dotado de exploração agropecuária e oferta de entretenimento e vivência do campo. Dentre os estados brasileiros, Minas Gerais desempenhou papel muito importante na história do país em termos de fazendas de café e pecuária leiteira. Sendo assim, há várias fazendas no estado que remontam séculos passados e muitas delas entenderam que oferecer experiência turística rural poderia ser outra fonte de 
MARKETING DE RELACIONAMENTO EM

HOTÉIS FAZENDA: UM FRAMEWORK A PARTIR

DA EXPERIÊNCIA
Iury Teixeira de Sevilha Gosling

Daniel Carvalho de Rezende

Marlusa de Sevilha Gosling

Francis Marcean Resende Barros Rauf Rodrigues Soares

renda (ROQUE; VIVAN, 2011). Dessa forma, verifica-se que as propriedades agrícolas mineiras têm relevância no cenário brasileiro do setor de turismo rural.

\section{Referencial teórico}

\subsection{Marketing de relacionamento}

A relação é uma interação mútua entre dois parceiros reciprocamente comprometidos. Ela se desenvolve quando o cliente percebe que existe uma correspondência de pensamento mútua com o seu fornecedor. Assim, escolher um parceiro com valores semelhantes pode manter a cooperação em longo prazo (HAKANSSO; SNEHOTA, 1999; GRONRÖOS, 2000; HUNT et al., 2006; WANG; ZHANG, 2017). A gestão de relações como prática empresarial tem gerando uma nova linha de pensamento, indicando que a questão pode ir para além de uma filosofia de negócio para se tornar uma nova cultura de marketing (MORGAN, 2000).

As correntes de pensamento em marketing inspiradoras do estudo das relações parecem bifurcar em duas grandes categorias, as que adotam uma dimensão transacional das relações (associada a uma perspectiva economicista) e as que referem a sua dimensão social (perspectiva mais relacional). Em razão da mudança de orientação do marketing e do pensamento mercadológico, os modelos transacionais de marketing têm dificuldade de encontrar espaço de desenvolvimento na nova economia, pois são baseados em premissas que não se sustentam mais. O Marketing de Relacionamento (MR) representa a migração do foco em transações para o foco em retenção, priorizando a manutenção e o aperfeiçoamento das relações com os clientes atuais (HOLLENSEN, 2003; EIRIZ; WILSON, 2006; DONALDSON; O’TOOLE, 2007; GUMMESSON, 2010; WU et al., 2013; ZEITHAML et al., 2014).

O crescente interesse das empresas em estabelecer vínculos de confiança e satisfação e tornar o cliente fiel à marca fez crescer também os estudos a respeito desse tipo de relacionamento entre empresa e cliente, surgindo uma nova escola de pensamento na área de marketing, denominada de MR (BARAKAT et al., 2011). Nas duas últimas décadas,ocorreu uma mudança nas teorias e nos conceitos do marketing que,aliadas com a mudança para o MR, se desenvolveramem um cenário onde as empresas estão buscando a abordagem do MR com a intenção de criarem vantagens e a fidelização dos clientes (GUELBERT, 2014).

O MR tem sido foco de estudos e de aplicações em diversas áreas de negócios e de convergência teórica com outras referências do marketing. Os principais motivadores desta nova tendência foram o aumento exacerbado da competição em diversos setores da indústria, motivado pela 
MARKETING DE RELACIONAMENTO EM

HOTÉIS FAZENDA: UM FRAMEWORK A PARTIR

DA EXPERIÊNCIA
Iury Teixeira de Sevilha Gosling

Daniel Carvalho de Rezende

Marlusa de Sevilha Gosling

Francis Marcean Resende Barros Rauf Rodrigues Soares

expansão dos mercados (internos e externos), e o aumento crescente do poder de compra da população. Novos paradigmas socioculturais surgiram, influenciando as organizações e suas atividades, bem como o relacionamento com seus stakeholders. Relacionamentos mais estreitos com clientes e parceiros de negócios assumem o papel de direcionadores da rentabilidade sustentável das relações de negócios, com a retenção de clientes passando a ser um conceito-chave que demanda a identificação de elementos que contribuam para seu aprimoramento teórico e prático (BERGAMO, 2017; TRIGO, 2017).

A adoção do MR pelas empresas requer uma cultura, estratégia e operações compatíveis com os seus princípios. Assim, é importante considerar os processos de negócios associados a ele (D'ANGELO et al., 2006; LARENTIS et al., 2018). O interesse em prezar uma relação de longo prazo não é exclusivo das organizações, pois o relacionamento duradouro é benéfico para ambas as partes. Mais do que gerar relacionamentos de longo prazo, o MR tem como objetivo gerar relacionamentos lucrativos entre os parceiros. Quanto mais as partes envolvidas estiverem motivadas a manter o relacionamento, menor o risco da dissolução da relação e maior a disposição delas investirem nesse relacionamento (KOTLER; KELLER, 2006; MIQUEL-ROMERO, et al. 2014; MOURA et al., 2014; ZEITHAML et al., 2014; SCHEERet al., 2015).

Essas relações que são desenvolvidas e mantidas entre as partes passam a ser uma excelente estratégia para as empresas, pois desenvolve chances maiores de fidelização de clientes e promove a competitividade das organizações envolvidas. Podem ser consideradas como ativos, pois o seu objetivo não consiste em vender mais para o maior número de clientes, e sim vender mais para o cliente atual, aumentando a participação desse cliente no resultado da empresa (GONÇALVES et al., 2012; BARRETO; CRESCITELLI, 2013; VALÉRIO, 2015).

O tema central relacionado aos conceitos e as perspectivas de MR está focado nas relações de cooperação e colaboração entre as empresas e seus clientes. Ou seja, o marketing relacional se refere a todas as atividades de marketing direcionadas para o estabelecimento, desenvolvimento e manutenção de relações bem-sucedidas (MORGAN; HUNT, 1994; PARVATIYAR, SHETH, 2001). As relações interorganizacionais envolvem múltiplas interações entre os indivíduos, seja no ambiente interno ou externo. O MR levou a um passo natural rumo ao paradigma de redes no marketing, também podendo ser assim conceituado como o marketing baseado em interações dentro da rede de relacionamentos (GUMMESSON, 2010; ACHROL; KOTLER, 2012; TRIGO, 2017).

Uma questão relevante na construção de alianças, por meio do MR, é a importância de se ouvir os clientes, não só os atuais, mas também os clientes em potencial e os clientes em poder da concorrência, não conquistados ou perdidos, (EVANS; LASKIN, 1994; YAMASHITA; GOUVÊA, 2007).

Observatório de Inovação do Turismo - Revista Acadêmica

Vol. XIV, n 1 , Abril - 2020 
MARKETING DE RELACIONAMENTO EM

HOTÉIS FAZENDA: UM FRAMEWORK A PARTIR

DA EXPERIÊNCIA
Iury Teixeira de Sevilha Gosling

Daniel Carvalho de Rezende

Marlusa de Sevilha Gosling

Francis Marcean Resende Barros Rauf Rodrigues Soares

O MR visa não só a troca, mas a retenção do cliente, de forma subjetiva (comportamental e emocional), e não simplesmente objetiva. A maximização do valor do ciclo de vida dos clientes rentáveis é um objetivo fundamental dessa abordagem. Mais do que conquistar novos clientes, a premissa do relacionamento consiste em manter o cliente já existente, instituindo uma conexão com o mesmo em busca de uma troca contínua. Para isso, esta abordagem do marketing utiliza da comunicação como principal prática, que objetiva ainda desenvolver comportamento de lealdade do cliente (PAYNE, 2005; GUELBERT, 2014; MEDEIROS et al., 2016; BERGAMO, 2017; CRUZ et al., 2017).

As ações estratégicas de comunicação no MR são empreendidas com a utilização de ferramentas integradas e sequenciais expostas ao consumidor, formando o desejo e a vontade do mesmo, de forma gradual e progressiva, até o momento da oferta (KOTLER; ARMSTRONG, 2014; VICENTE, 2015). O MR configura uma grande contribuição ao pensamento e a prática de marketing, desafiando as estratégias do passado, em razão de relacionamentos em constantes mudanças. Parece ainda mais significativo quando os relacionamentos são considerados complexos e multifacetados. Representa uma série flexível de conceitos e ideias, em vez de uma teoria fixa e inflexível. É um processo contínuo de engajamento em atividades de colaboração com consumidores intermediários ou finais para criar ou desenvolver valor econômico, social ou psicológico para ambos. Ele concebe novos valores junto aos clientes individuais, compartilhando de seus benefícios durante a parceria (GORDON, 1998; EGAN, 2011; SHETH et al., 2012; PAYNE; FROW, 2017).

\subsection{Qualidade do serviço}

A qualidade é uma das principais formas de uma empresa se diferenciar no mercado. Ela envolve a identificação e a satisfação das necessidades humanas e sociais, conferindo valor superior a um bem ou serviço. O mais importante passo para a prestação de um serviço de qualidade é conhecer a expectativa do cliente (CURY, 2011; KOTLER; ARMSTRONG, 2014; ZEITHAML et al., 2014). A qualidade percebida é um importante antecedente da confiança, pela relação existente entre valores pessoais dos consumidores e a importância atribuída por estes. Representa um fator crucial na construção e manutenção de vantagens competitivas (CHURCHILL; PETER, 2000; NETO; MOURA, 2004; XAVIER JUNIOR, 2006; SOLOMON, 2016).

Por meio da medição da percepção do usuário, é possível identificar os melhores caminhos para a qualidade dos serviços prestados, diminuindo com isso, o descrédito e aumentando a confiança dos usuários. Assim, a compreensão da percepção do cliente faz com que a gestão de serviços esteja centrada na qualidade (NARANG, 2012; ROSALEM, 2013). 
MARKETING DE RELACIONAMENTO EM

HOTÉIS FAZENDA: UM FRAMEWORK A PARTIR

DA EXPERIÊNCIA
Iury Teixeira de Sevilha Gosling

Daniel Carvalho de Rezende

Marlusa de Sevilha Gosling

Francis Marcean Resende Barros Rauf Rodrigues Soares

Foi desenvolvida por Parasuraman et al. (1988), uma escala denominada de Service Quality Scale (SERVQUAL), que consiste em um instrumento para a mensuração da qualidade percebida pelo consumidor (Figura 1). Essa escala demonstra o que o cliente espera na prestação do serviço e o que ele realmente percebe (MELO; MUNIZ, 2017). O modelo Servqual fornece um esqueleto básico por meio do seu formato de expectativas e percepções que inclui sentenças para cinco dimensões da qualidade percebida: confiabilidade (consistência no desempenho), responsividade (atender às necessidades do consumidor conforme sua percepção), segurança (confiança no serviço e sua credibilidade), empatia (comprometimento da empresa com o serviço) e tangibilidade (a aparência das evidências físicas, instalações e equipamentos) (LOURES, 2009; ZEITHAML et al., 2014).

Quadro 1. Dimensões da SERVQUAL

\begin{tabular}{|c|c|}
\hline Dimensão & Significado \\
\hline Tangíveis & Facilidades físicas, equipamentos e aparência dos funcionários. \\
\hline Confiabilidade & Execução do serviço prometido de forma confiável e precisa. \\
\hline Responsividade & Disponibilidade para ajudar os clientes e prestar um serviço rápido. \\
\hline Segurança & Conhecimento, cortesia e capacidade de inspirar confiança dos funcionários. \\
\hline Empatia & Atendimento e atenção individualizada oferecidos aos seus clientes. \\
\hline
\end{tabular}

A Servqual ganhou maior destaque em razão da sua grande versatilidade de adaptação para os mais diversos ramos de serviços, e por apresentar os maiores índices de confiabilidade, sendo testado e validado em diversos tipos de prestação de serviços (ROSALEM, 2013). Para avaliações específicas, faz-se necessário considerar a particularidade a cada caso, customizando os itens utilizados no processo de mensuração da qualidade (CARMAN, 1990).

\subsection{Valor percebido}

Em geral, o MR é um conjunto de processos que envolvem a comunicação, a criação e a entrega de algum valor para o cliente (KOTLER; KELLER, 2006; MIQUEL-ROMERO et al., 2014; MOURA et al., 2014; ZEITHAML et al., 2014; SCHEER et al., 2015).

O valor percebido pelo cliente pode ser definido como a diferença entre as percepções do cliente quanto aos benefícios da compra e uso dos produtos e serviços e os custos envolvidos no processo de aquisição (CHURCHILL; PETER, 2000; NETO; MOURA, 2004; XAVIER JUNIOR, 2006; SOLOMON, 2016).

Quadro 2. Dimensões do valor percebido

\begin{tabular}{|c|c|}
\hline Dimensão & Significado \\
\hline Emocional & Geração de sentimentos ou estados afetivos. \\
\hline
\end{tabular}


MARKETING DE RELACIONAMENTO EM

HOTÉIS FAZENDA: UM FRAMEWORK A PARTIR

DA EXPERIÊNCIA
Iury Teixeira de Sevilha Gosling

Daniel Carvalho de Rezende

Marlusa de Sevilha Gosling

Francis Marcean Resende Barros Rauf Rodrigues Soares

\begin{tabular}{|c|c|}
\hline Social & Melhoria do autoconceito social. \\
\hline Econômico & Redução dos custos percebidos de curto e longo prazo. \\
\hline Funcional & Qualidade percebida e performance esperada do produto. \\
\hline \multicolumn{2}{c}{ Fonte: Sweeney e Soutar (2001, p. 211$).$}
\end{tabular}

Além do aspecto econômico, Sweeney e Soutar (2001) destacam outros três tipos de valor percebido (Quadro 2). O valor emocional reflete o atributo de um produto que traria prazer, relaxamento e bem-estar em razão de seu uso. $\mathrm{O}$ valor social está relacionado à sensação de aceitação e melhoria da forma como o indivíduo é percebido. O valor econômico está voltado para uma boa relação custo/benefício percebida, em que o dispêndio financeiro é valorizado. $\mathrm{O}$ valor funcional reflete as características do produto e se relaciona com a qualidade, envolve questões relativas aos padrões do produto, sua execução em tempo hábil e sua consistência.

\subsection{Satisfação}

A satisfação do consumidor é a atitude referente a um produto ou serviço após sua compra e uso, por meio do julgamento e da avaliação pós-escolha. Ela depende do desempenho do produto ou serviço em relação às suas expectativas (MOWEN; MINOR, 2003; KOTLER; ARMSTRONG, 2014).

O MR privilegia a interação com o seu cliente, com o objetivo de desenvolver, especialmente para ele, um conjunto de valores que o levarão à satisfação e longevidade do seu relacionamento com a empresa. Para que este relacionamento tenha uma boa aceitação, o cliente tem que se sentir satisfeito com a oferta do fornecedor e se sentir recompensado pela manutenção do relacionamento (MADRUGA, 2010; MOURA et al., 2014).

À medida que os clientes ficam satisfeitos ao longo do tempo, torna-se mais difícil incrementar esta satisfação, e por isso, a empresa deve avaliar continuamente os efeitos da satisfação do cliente, com o intuito de manter a sua lealdade. A manutenção do cliente é um fator estratégico no MR, pois os custos para uma empresa atrair um novo cliente são, muitas vezes, superiores aos custos para a manutenção de um cliente atual (LOVELOCK; WRIGHT, 2003; KUMAR, 2016).

Clientes insatisfeitos podem passar para a concorrência e disseminar um boca a boca negativo enquanto clientes satisfeitos são mais propensos a permanecer fiéis e gerar uma série de resultados positivos para a empresa, como o boca a boca positivo e lealdade. Na qualidade do relacionamento entre empresa e cliente é que nasce a fidelidade, que é a vontade de um cliente de continuar prestigiando uma empresa durante um período prolongado, consumindo e recomendando voluntariamente seus produtos e serviços (LOVELOCK; WRIGHT, 2003, HEITMANN et al., 2007).

No processo de construção de relacionamento, é importante adotar uma visão mais holística, pois nos aspectos comportamentais de tal construção, a satisfação tem posição privilegiada. $\mathrm{O}$ 
MARKETING DE RELACIONAMENTO EM

HOTÉIS FAZENDA: UM FRAMEWORK A PARTIR

DA EXPERIÊNCIA
Iury Teixeira de Sevilha Gosling

Daniel Carvalho de Rezende

Marlusa de Sevilha Gosling

Francis Marcean Resende Barros Rauf Rodrigues Soares

desempenho da organização em oferecer possibilidades de confirmação da expectativa do consumidor, contribui para a geração da satisfação desse cliente (LOVELOCK; WRIGHT, 2003; KUMAR et al., 2013; OLIVER, 2014).

\subsection{Cocriação}

$\mathrm{Na}$ constante busca por compreender as relações entre os atores do mercado, o pensamento de marketing se moveu em direção às relações de trocas dinâmicas que envolvem processos de realização e troca de habilidades e/ou serviços, nos quais o valor é cocriado com o consumidor. Esta nova lógica centrada na importância do relacionamento ou interações repetidas surge como um paradigma que contesta a lógica dominante, que é baseada na troca de bens, cujo marketing é visto como uma atividade de tomada de decisão e entende o produto como criador de valor (VARGO; LUSCH, 2004; AMADO, 2017).

A cocriação de valor é um processo que não acontece de modo aleatório, podendo ser vista como uma coordenação do comportamento dos stakeholders, com atividades planejadas e disponibilização de um ambiente propício ao alcance dos resultados desejados em conjunto (RAMASWAMY; COUTINHO, 2011; NEGHINA et al., 2015; HIGUCHI, 2017).

Cocriação é a união da criação e do desenvolvimento do valor em que a perspectiva de criação não é somente da organização, mas leva em consideração os consumidores e demais stakeholders como partes integrantes dos recursos de produção de valor. O seu principal propósito consiste em criar um valor superior aquele que cada ator poderia alcançar individualmente (SALVADO, 2013; RAMASWAMY; OZCAN, 2014; NEGHINA et al., 2015; AMADO, 2017).

Existe na cocriação a descentralização da criação de valor, já que tradicionalmente as empresas detêm o poder de avaliação, e quando a empresa decide tornar-se cocriativa, passa por um longo processo de mudança, que requer o desenvolvimento de novas habilidades, primeiramente centrando-se na experiência com os indivíduos e não em seus produtos e serviços. $O$ caráter experiencial do consumidor na criação de valor demanda a necessidade de uma compreensão profunda do papel das suas experiências no processo de cocriação de valor (RAMASWAMY; GOUILLART, 2010; ARAUJO; JESUS, 2016; SCARTON, 2016).

A cocriação é um processo que pode ser atrativo para organizações das mais variadas naturezas, visto que as ideias geradas refletem melhor as necessidades reais ou imaginárias dos clientes. É uma poderosa abordagem para a inovação aberta, podendo produzir impactos positivos na performance organizacional e gerar inovadores modelos de distribuição e comercialização (SALVADO, 2013; AMADO, 2017). 
MARKETING DE RELACIONAMENTO EM

HOTÉIS FAZENDA: UM FRAMEWORK A PARTIR

DA EXPERIÊNCIA
Iury Teixeira de Sevilha Gosling

Daniel Carvalho de Rezende

Marlusa de Sevilha Gosling

Francis Marcean Resende Barros

Rauf Rodrigues Soares

\section{Metodologia}

A Figura 1 representa o design do estudo, mostrando o que se busca encontrar a partir dos dados tendo em vista a teoria utilizada.

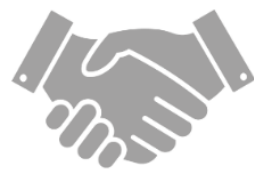

Aporte teórico

Marketing de relacionamento

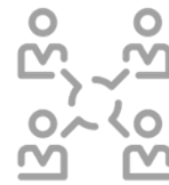

Coleta de dados Grupos focais

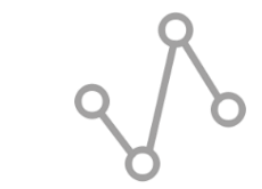

Tratamento dos dados

Análise de conteúdo
Insights

Framework

Figura 1. Design do estudo

Fonte: Elaborado pelos pesquisadores (2018)

Desenvolveu-se uma pesquisa exploratória, uma vez que se teve como objetivo formular problemas de investigação para estudos futuros, tendo como base o desenvolvimento de conceitos e ideias utilizando dados qualitativos (GIL, 2008). Quanto à natureza, tratou-se de uma pesquisa qualitativa, pois buscou melhorar a compreensão sobre o contexto do problema (MALHOTRA, 2012). Os procedimentos de coleta e análise de dados estão descritos a seguir.

\subsection{Coleta de dados}

Os dados da pesquisa foram primários, originados pelos pesquisadores tomando como ponto de partida o problema de pesquisa (MALHOTRA, 2012). A coleta foi realizada por meio de grupos focais. Para Gil (2008), os grupos de foco são utilizados em estudos exploratórios para melhorar a compreensão do problema e fomentar hipóteses e instrumentos de coleta de dados. Além disso, a utilização de grupos focais está alinhada com a pesquisa qualitativa no sentido de investigar um tema em profundidade.

Nesta pesquisa, foram conduzidos grupos focais com seis grupos de alunos do curso Bacharelado em Administração de uma instituição federal. Os grupos foram compostos por cinco a seis participantes. Especificamente, foram utilizados minigrupos focais, que, segundo Corbetta (2003), são adequados para que todos os participantes expressem suas ideias de maneira confortável.

O Quadro 3 mostra o roteiro aplicado. As primeiras perguntas estão relacionadas ao contexto de experiência em hotéis como um todo, filtrando-se, nas demais, a realidade dos hotéis fazenda. Os itens $2.1,2.2$ e 5.1 representam probes, que são pontos pelos quais o moderador do grupo focal pode direcionar a resposta, caso a discussão não tenha gerado respostas para esses pontos. No geral, buscou- 
MARKETING DE RELACIONAMENTO EM

HOTÉIS FAZENDA: UM FRAMEWORK A PARTIR

DA EXPERIÊNCIA
Iury Teixeira de Sevilha Gosling Daniel Carvalho de Rezende

Marlusa de Sevilha Gosling

Francis Marcean Resende Barros Rauf Rodrigues Soares

se abordar os quatro construtos identificados no referencial teórico, a fim de se coletar os dados necessários para compreendê-los e analisá-los no contexto da experiência em hotéis fazenda.

\subsection{Análise dos dados}

Após a realização, gravação e transcrição dos dados, utilizou-se a técnica de análise de conteúdo para tratar os dados. A análise de conteúdo, segundo Bardin (2011), envolve as etapas de pré-análise, exploração do material e o tratamento dos resultados.

Quadro 3. Roteiro do grupo de foco

\begin{tabular}{|c|c|}
\hline & Pergunta \\
\hline \multirow{4}{*}{$\begin{array}{l}\mathbf{H} \\
\mathbf{o} \\
\mathbf{t} \\
\mathbf{e} \\
\mathbf{i} \\
\mathbf{s} \\
\mathbf{g} \\
\mathbf{e} \\
\mathbf{r} \\
\mathbf{a} \\
\mathbf{l}\end{array}$} & 1. Quando se hospedam em um hotel em viagens de lazer, o que vocês esperam encontrar? \\
\hline & $\begin{array}{l}\text { 2. O que caracteriza uma boa estadia em viagens de lazer? } \\
\text { 2.1 Quais são os elementos principais? } \\
\text { 2.2 O que não pode faltar? }\end{array}$ \\
\hline & $\begin{array}{l}\text { 3. Em experiências de viagens de lazer, quando pensam em um hotel, vocês se lembram de algum em } \\
\text { específico? Qual? Por que se lembram desse? }\end{array}$ \\
\hline & 4. Que atributos vocês buscam em um hotel para se hospedarem em viagens de lazer? \\
\hline \multirow{18}{*}{$\begin{array}{l}\mathbf{H} \\
\mathbf{o} \\
\text { t } \\
\text { é } \\
\mathbf{i} \\
\mathbf{s}\end{array}$} & $\begin{array}{l}\text { 5. Qual tipo de experiência um hotel fazenda deve proporcionar para os hóspedes? } \\
\text { 5.1 Quais sensações e emoções? }\end{array}$ \\
\hline & 6. Quais atividades de lazer um hotel fazenda deve oferecer? \\
\hline & 7. O que as pessoas buscam ao se hospedarem em um hotel fazenda? \\
\hline & 8. Aos que já foram: o que mais gostaram em um hotel fazenda? O que foi mais marcante? \\
\hline & 9. Aos que já foram: o que menos gostaram? \\
\hline & 10. Com quem vocês já foram a um hotel fazenda? Com quem gostariam de ir, caso nunca tenham ido? \\
\hline & 11. Aos que já foram: o que o hotel fazenda representou para vocês? \\
\hline & $\begin{array}{l}\text { 12. Aos que já foram: a estadia no hotel fazenda modificou você em algum aspecto? Aos que nunca } \\
\text { foram: o que esperam de modificações no próprio comportamento a partir dessa experiência? }\end{array}$ \\
\hline & 13. O que lhe fariam querer voltar (ou ir) a um hotel fazenda? \\
\hline & 14. O que consideram importante que um bom hotel fazenda ofereça? \\
\hline & 15. Qual tipo de gastronomia deveria ser ofertado por um hotel fazenda? \\
\hline & 16. Qual tipo de ofertas personalizadas um hotel fazenda deveria fornecer? \\
\hline & 17. Que atributos de um hotel fazenda fariam você não ir ou não voltar? \\
\hline & $\begin{array}{l}\text { 18. Sabendo que a cocriação é a participação efetiva do cliente nas ofertas finais de produtos ou serviços, } \\
\text { como pode acontecer a cocriação em hotéis fazenda? }\end{array}$ \\
\hline & $\begin{array}{l}\text { 19. Aos que já foram: você ou seus acompanhantes participaram de alguma atividade no hotel fazenda } \\
\text { que pudesse ser classificada como cocriação? Quais? }\end{array}$ \\
\hline & 20. Qual a importância que este tipo de estadia tem para o bem-estar das pessoas? \\
\hline & 21. O que faria você classificar sua experiência no hotel fazenda como única? \\
\hline & iente em hotéis fazenda? Por quê? \\
\hline
\end{tabular}

Fonte: Elaborado pelos pesquisadores (2018) 
MARKETING DE RELACIONAMENTO EM

HOTÉIS FAZENDA: UM FRAMEWORK A PARTIR

DA EXPERIÊNCIA
Iury Teixeira de Sevilha Gosling

Daniel Carvalho de Rezende

Marlusa de Sevilha Gosling

Francis Marcean Resende Barros Rauf Rodrigues Soares

Na pré-análise, realizou-se a seleção do material e dos procedimentos a serem executados. $\mathrm{Na}$ exploração do material, foram considerados, para categorização, os construtos subjacentes ao marketing de relacionamento tratados no referencial teórico deste trabalho. No tratamento dos resultados, buscou-se o confrontamento das narrativas com o referencial teórico, culminando na proposição de um framework teórico aplicável ao contexto dos hotéis fazenda com base nas categorias selecionadas.

A análise foi feita utilizado o software NVivo, versão 10.0.638.0, que funciona como um painel de integração para os dados, tornando possível a classificação por meio de nós. Cada nó foi representado por uma categoria, composto por nós secundários que representaram as subdimensões de um construto (por exemplo: a qualidade é um nó, enquanto os elementos tangíveis formam um subnó).

Com base nesses procedimentos, foi possível analisar os termos mais frequentes em cada nó, auxiliando na construção do framework teórico sugerido ao final da seção seguinte.

\section{Análise e discussão dos resultados}

A análise do conteúdo dos grupos focais se concentra nas categorias de qualidade percebida do serviço, valor percebido, satisfação e cocriação, estabelecidas a priori.

Em relação à qualidade percebida do serviço, destacaram-se os elementos tangíveis e os aspectos de responsividade, em que os grupos foram convergentes ao pontuar que o conforto, traduzido pelas características físicas dos hotéis, e o bom atendimento são fatores importantes na composição do hotel fazenda.

$\mathrm{Na}$ dimensão do valor percebido, o mais mencionado foi o emocional, muito em razão da sensação de fuga da rotina e das boas sensações exprimidas em decorrência da experiência em hotéis fazenda, como o relaxamento e o prazer pelas atividades oferecidas. O valor funcional, medido em termos de qualidade (SWEENEY; SOUTAR, 2001), retratou com solidez o quesito consistência nas atividades propostas por um hotel fazenda, envolvendo, de um modo geral, os aspectos particulares de uma experiência dessa espécie, como o contato com o meio-ambiente, os animais e a natureza.

O conceito de satisfação foi fortemente aproximado com a criação de expectativas, presente em grande parte das narrativas. As discussões realizadas no grupo focal mostram que tanto os aspectos da qualidade, quanto a percepção de valor são elementos importantes para o alcance das expectativas e, consequentemente, para levar o indivíduo a perceber a experiência como satisfatória.

A cocriação, por sua vez, não foi considerada pelos grupos em seu sentido amplo. Seu significado foi duramente restrito aos feedbacks enviados aos hotéis e a algumas iniciativas menores e isoladas de participação, sobretudo por parte das crianças. De maneira saliente, as propostas de 
MARKETING DE RELACIONAMENTO EM

HOTÉIS FAZENDA: UM FRAMEWORK A PARTIR

DA EXPERIÊNCIA
Iury Teixeira de Sevilha Gosling

Daniel Carvalho de Rezende

Marlusa de Sevilha Gosling

Francis Marcean Resende Barros Rauf Rodrigues Soares

cocriação consideradas pelos grupos focais foram retratadas na possibilidade de preparação de algumas refeições em conjunto.

\subsection{Qualidade do serviço}

No âmbito da qualidade, todas as dimensões identificadas por Parasuraman, Zeithaml e Berry (1988) foram encontradas. A estrutura dos hotéis fazenda foi considerada primordial, destacando-se as menções às instalações confortáveis, tais como camas, frigobar, TV, internet de qualidade, toalhas e roupas de cama limpas. Foram pontuadas também a qualidade no atendimento e a grande oferta de comida, incluindo todas as refeições. Os aspectos relativos às dimensões de confiabilidade, segurança e empatia foram menos mencionados, embora enfatizados quando foram citados. A qualidade foi o construto mais abordado pelos participantes dos grupos focais, corroborando a importância de que a gestão dos serviços esteja centrada nos aspectos da qualidade (NARANG, 2012; ROSALEM, 2013).

Tangíveis: Esta dimensão da qualidade foi presente em diversos trechos dos grupos focais. Dentre os elementos mais esperados e considerados nos hotéis, destacaram-se o conforto, a limpeza e a alimentação (café da manhã, restaurantes, comidas e bebidas). Foi pontuado que os quartos deveriam ser bem equipados. Ao todo, a palavra conforto, no contexto das instalações do hotel, foi mencionada 25 vezes.

A infraestrutura foi muito citada, e uma observação particular que ocorreu no Grupo 1 abordou que ela "[...]não pode ser moderna. [...]. Tem que ter experiência de fazenda", o que foi reforçado pela constatação de que o hotel fazenda não está muito voltado ao luxo, mas ao conforto. Em relação à gastronomia, aspectos tangíveis relacionados a culinária também foram pontuados. Não haveria problema em consumir o mesmo tipo de alimento que se consome fora do hotel fazenda, desde que ela seja "[...]feita em panela de cobre, de barro, no fogão a lenha" (Grupo 1). A falta de limpeza, isolamento acústico para sons e presença de mofo também foram aspectos físicos que fariam os participantes não irem ou deixarem de voltar.

Confiabilidade: Essa dimensão foi uma das menos expostas nos grupos focais. Os relatos versam sobre a experiência em hotéis, sendo que a que é entendida como boa é aquela "[...]que não tenha contratempos, nem nada! Que seja tudo muito rápido e muito certinho" (Grupo 4), com "[...]um serviço rápido com soluções rápidas quando tiver algum problema" (Grupo 4).

Como dimensão da qualidade, é natural que se relacione com outras dimensões, como a dos aspectos tangíveis. Isso é visto em outro comentário do Grupo 4: “[...]a gente espera conforto e que quando tiver algum problema que resolva rápido".

Responsividade: Foi considerado que é importante que haja "[...]um bom serviço de atendimento, de recepção, serviço de quarto" (Grupo 1). O bom atendimento é colocado como um 
MARKETING DE RELACIONAMENTO EM

HOTÉIS FAZENDA: UM FRAMEWORK A PARTIR

DA EXPERIÊNCIA
Iury Teixeira de Sevilha Gosling

Daniel Carvalho de Rezende

Marlusa de Sevilha Gosling

Francis Marcean Resende Barros

Rauf Rodrigues Soares

elemento importante, que deve caracterizar uma viagem. Assim, um atendimento percebido como ruim pode fazer com que o indivíduo não volte ou não tenha intenção de ir pela primeira vez. Também foram mencionados serviços em restaurantes de hotéis.

Relacionando-se com os aspectos tangíveis, a combinação de atendimento ruim com ambiente sujo seria outro aspecto que impediria a revisita ou a primeira visita ao hotel fazenda. Relacionando-se também com a satisfação, este trecho do Grupo 2 ilustra a relação entre esses construtos: “[...]eu acho que gostaria de ir a um hotel onde eu posso sentir me muito confortável e satisfeita com o atendimento".

Segurança: Nessa dimensão, maior atenção foi dada às situações em que as crianças são levadas ao hotel fazenda e necessitam do acompanhamento de monitores, mostrando que há presença de confiança na capacidade dos funcionários:

E quando você tem criança é bom ocupar as crianças e relaxar ao mesmo tempo... Você deixa com os caras lá [monitores] (Grupo 1).

Ter alguém pra cuidar, né [monitores]. Tem os monitores pras criancinhas, [...], os pais ficam de boa (Grupo 4).

É, deixa pro monitor, e esquece (Grupo 6).

Também foram mencionados pontos relacionados à segurança. Em termos de urgências de saúde: "Eu acho que tem que ter o mínimo de treinamento de primeiros socorros. É um atributo que importaria pra mim. Porque, normalmente, é num lugar longe, então poderia não dar tempo de levar no hospital" (Grupo 1). Além disso, em relação às atividades específicas que os hotéis fazenda oferecem, como os passeios a cavalo ou a tirolesa, um trecho do Grupo 4 exprime a preocupação com a segurança: "Acho que o hotel teria que ter cuidado ao proporcionar essas experiências diferentes, pra não ter o risco de dar errado, entende?".

Empatia: A dimensão que destaca a atenção oferecida pelos funcionários se manifestou de diversas maneiras. Os trechos a seguir, extraídos do Grupo 6, destacam a importância da atenção dos funcionários para os participantes em relação ao que poderia desmotivar a ida ao hotel fazenda.

Falta de atenção no atendimento, acho que é uma coisa crucial.

Se eu vou ficar hospedado em um lugar, eu quero ser atendido com muita atenção.

Isso... É... Quero que a pessoa seja educada e atenciosa comigo.

Eu acho que no hotel fazenda isso faz toda a diferença, essa questão da hospitalidade mesmo. Criar esse ambiente família, integrador.

Foi considerado que existe a expectativa por atividades diferenciadas, em que o hotel, no sentido de lazer, deve pensar em agregar algum atrativo em seu conteúdo. Pensando no público infantil, também foi mencionado um "serviço de recreação para crianças" (Grupo 1), além de pacotes focados em crianças por serem consideradas um público costumeiro dos hotéis fazenda. Um caso 
MARKETING DE RELACIONAMENTO EM

HOTÉIS FAZENDA: UM FRAMEWORK A PARTIR

DA EXPERIÊNCIA
Iury Teixeira de Sevilha Gosling

Daniel Carvalho de Rezende

Marlusa de Sevilha Gosling

Francis Marcean Resende Barros

Rauf Rodrigues Soares

específico no Grupo 5 destacou a "[...]assistência às atividades", em específico, que os hotéis ofereçam "[...]assistência para atividades de ecoturismo" (Grupo 5). Em relação à alimentação, foi observado que "[...]às vezes, observar uma restrição alimentar também é uma forma de personalizar" (Grupo 1).

\subsection{Valor percebido}

Foram considerados os valores emocional, social, econômico e funcional da experiência identificados por Sweeney e Soutar (2001). O valor social foi o mais enfatizado em termos de convivência com a família e com novas pessoas. No emocional, destacou-se a sensação de liberdade e desaceleração do ritmo. O valor econômico foi visto em razão da relação custo/benefício e da expectativa por promoções e descontos. Já o valor funcional refletiu as atividades intrínsecas ao hotel fazenda, em que as discussões se voltaram de forma recorrente para as obrigações específicas que essa atividade deve cumprir para tornar a experiência consistente.

Valor emocional: Nessa dimensão, destacam-se as percepções de lazer e prazer nas atividades oriundas da estadia no hotel fazenda. Foi possível observar a presença dos indicadores de valor emocional colocados por Sweeney e Soutar (2001), em que foi abordado como as pessoas gostariam que o hotel fazenda fosse e os fatores motivadores para seu uso, além das sensações de relaxamento, prazer e bem-estar. É destacado o contato com os animais, com a natureza e com o ar livre. Dentre as atividades, destaca-se o passeio a cavalo, o arvorismo, tirolesa, pescaria, charrete e a vivência da rotina da fazenda. Em geral, um "[...]contato com a natureza, tranquilidade, ambiente tranquilo, relaxante" (Grupo 5). Também se mencionam aspectos relativos ao estado de espírito, em termos de relaxamento, renovação das energias e desaceleração do ritmo corriqueiro, como extraído a seguir:

Eu acho que foi revitalizante. Que eu entrei lá bem estressada e saí de lá mais energizada (Grupo 1)

O contato com a natureza, talvez. Voltei de lá contando para os amigos o tanto de coisa que tinha feito com os animais... Tirado leite de vaca, muito legal. Apreciar o silêncio. Perceber que é muito bom, que a cidade é muito barulhenta (Grupo 3).

Acho que é só renovar a energia mesmo, ter mais contato com as pessoas, só parar um pouco o que você está fazendo e refletir (Grupo 4).

Essa tranquilidade, né. Pensar mais em diminuir o ritmo mesmo. É, esse é o principal, desacelerar (Grupo 6).

Quanto à transformação que pode ser causada pela visita ao hotel fazenda, os participantes abordaram o abandono ao stress e a revitalização das energias. Também significa uma oportunidade de refletir e interagir com as pessoas, criando uma interface relacionada ao valor social. A diversão e a despreocupação também foram colocadas como elementos que não podem faltar na experiência em 
MARKETING DE RELACIONAMENTO EM

HOTÉIS FAZENDA: UM FRAMEWORK A PARTIR

DA EXPERIÊNCIA
Iury Teixeira de Sevilha Gosling

Daniel Carvalho de Rezende

Marlusa de Sevilha Gosling

Francis Marcean Resende Barros

Rauf Rodrigues Soares

um hotel. De forma geral, o hotel fazenda proporciona "[...]fazer coisas que geralmente não se faz onde se mora" (Grupo 2), mostrando uma interação com o valor funcional percebido pela atividade.

Valor social: O fator social também foi apontado como motivador da busca por esse tipo de hospedagem, uma vez que os respondentes alegaram buscar momentos de lazer em família, aproximação com pessoas queridas e importantes e até mesmo criar novas relações.

Eu acho que foi a experiência de poder estar reunida com a família e ter aquele momento. Por mais que cada um estivesse fazendo sua atividade, a gente estava fazendo algo no mesmo espaço, algo que a gente não fazia a muito tempo, que a rotina não permite a gente fazer, então a gente estava tendo essa oportunidade (Grupo 1).

A oportunidade de ter saído da rotina e reunir uma parte da minha família. A oportunidade de conhecer mais pessoas (Grupo 2).

A gente ficou amigo de todo mundo do hotel (Grupo 3).

A experiência em hotéis fazenda foi colocada até como uma intervenção terapêutica, sobretudo para as pessoas mais velhas, uma vez que representa uma nova possibilidade de socialização. Da mesma forma, para os mais jovens, um trecho do Grupo 1 ilustra: "Aí você interage com a galera da sua idade. Na época que você é adolescente, isso é bem importante".

Valor econômico: Em relação ao valor econômico percebido, foi indicado como atrativo a possibilidade de realização de promoções por parte dos hotéis em relação a descontos para famílias e para períodos específicos, tais como férias e feriados. Essa busca está alinhada com o significado do valor econômico percebido definido por Sweeney e Soutar (2001), que pontua a percepção de preços razoáveis e a sensação do dinheiro estar sendo valorizado. Observações sobre preço e relação custo/benefício também foram feitas em alguns trechos dos grupos focais. No Grupo 2, um participante abordou: "[...]por exemplo, eu vou me hospedar no hotel dentro das redondezas que eu acho melhor escolha, tem melhor custo/benefício perto daquilo que eu quero visitar".

Quanto às promoções, foi abordado pelo Grupo 3:

Eu iria se tivesse uma promoção. [...] se você já se hospedou aqui, se hospede novamente e ganhe 50\% de desconto. Aí eu iria. Seria diferencial para eu voltar. Porque se eu não tivesse nenhum atrativo monetário também eu procuraria outro.

A relação custo/benefício também foi colocada como atributo do serviço, combinado com uma infraestrutura decente. Em geral, um participante do Grupo 6 condensou a relação entre o preço e os outros atributos dos hotéis: "[...]acho que esse são os atributos, preço acessível, o conforto, e o custo/ benefício de ser um hotel bom, confortável e ao mesmo tempo com preço acessível".

Valor funcional: Em relação à sua funcionalidade, os pontos principais relacionados às características e aos atributos que os hotéis fazenda devem ter versam sobre questões relacionadas à 
MARKETING DE RELACIONAMENTO EM

HOTÉIS FAZENDA: UM FRAMEWORK A PARTIR

DA EXPERIÊNCIA
Iury Teixeira de Sevilha Gosling

Daniel Carvalho de Rezende

Marlusa de Sevilha Gosling

Francis Marcean Resende Barros

Rauf Rodrigues Soares

fazenda, a um local bucólico, como natureza, campo, passeio a cavalo, acesso às cachoeiras, pesca e outras atividades relacionadas a esse meio. O principal aspecto investigado foi a consistência.

Os grupos consideraram que a estadia em hotéis fazenda deve se pautar em uma imersão no local à medida que os hospedes não intentem sair do estabelecimento. Assim, o hóspede busca conforto, lazer, tranquilidade, boa comida a um fácil acesso, sem sair do local. Foi mencionado que ao escolher "[...]um hotel fazenda ou um resort, não se pensa em sair de lá para procurar as coisas" (Grupo 5). A busca pelo serviço do hotel fazenda, como abordado no aspecto emocional, visa um distanciamento do caos urbano, como exposto nos trechos seguintes.

\footnotetext{
Eu acho importante que hotel fazenda ofereça diferentes atividades, esportes, jogos, caminhadas ecológicas e demais coisas. Alguma atividade radical, se tiver oportunidade, ou então, só alguma trilha, [...] conectado à natureza (Grupo 2).

Lazer diversificado. Uma coisa assim, sei lá, uma coisa diferente pra fazer. Aqueles serviços de andar a cavalo, umas coisas rústicas (Grupo 3).

Acho que a "pegada" do hotel fazenda é diferente de hotéis da cidade porque a ideia é você ficar lá dentro, né? Então, tem que ter tipo outras coisas pra você fazer, tipo, umas bicicletas. [...] outras formas de entretenimento mesmo (Grupo 4).

Algum tipo de ecoturismo, tipo andar a cavalo. Hotel fazenda pra mim é a mesma coisa de "[...] eu quero ficar perto da natureza". (Grupo 5)
}

Também é envolvida a sensação de uma experiência marcante: "O que mais marcou foi o contato com a natureza e a possibilidade de fazer algumas atividades que a gente não tem acesso num centro urbano, como andar a cavalo, canoagem, caiaque, rafting" (Grupo 5). Por isso, esse mesmo fator chama atenção para a importância de se manter atividades em curso: "Atividades que vão ocupar seu tempo. Igual eu falei, quando vou num lugar afastado não tem muito a se fazer fora, não. [...] então você tem que estar lá com atividade disponível o tempo todo" (Grupo 6).

No sentido de uma completa diferenciação em relação ao espaço urbano, relacionando-se com o valor econômico, foi abordado que a forma de cobrança também deve ser mais funcional: "Ficar pagando cada prato e pesando, parece que você tá na cidade. Você não pesa nada na fazenda" (Grupo $1)$.

Nesse sentido, pela especificidade da atividade do hotel fazenda, confirma-se o papel do valor percebido no MR (KOTLER; KELLER, 2006; MIQUEL-ROMERO, et al. 2014; MOURA et al., 2014; ZEITHAML et al., 2014; SCHEER et al., 2015).

\subsection{Satisfação}

O Quadro 4 mostra os diversos contextos em que elementos relativos à satisfação foram tratados.

Quadro 4. Aspectos da satisfação em hotéis fazenda

Contexto $\quad$ Trechos

Observatório de Inovação do Turismo - Revista Acadêmica

Vol. XIV, n 1 , Abril - 2020 


\begin{tabular}{|l|l|}
\hline $\begin{array}{l}\text { Elementos que } \\
\text { caracterizam uma boa } \\
\text { estadia }\end{array}$ & $\begin{array}{l}\text { "Acho que quando atende a expectativa, tipo assim, você pensa que o hotel vai ser } \\
\text { daquele jeito, aí se ele realmente foi pelo menos perto daquilo que você esperou, } \\
\text { você teve uma boa estadia" / "Satisfação e conforto, porque eu fico satisfeita, } \\
\text { confortável" (Grupo 2). }\end{array}$ \\
\hline $\begin{array}{l}\text { O que faria o } \\
\text { participante ir ou voltar } \\
\text { a um hotel fazenda }\end{array}$ & $\begin{array}{l}\text { "Se o atendimento for bom, se o lugar for bom. Se tiver boas atividades, alguma } \\
\text { coisa assim. Superar minhas expectativas" (Grupo 3). }\end{array}$ \\
\hline $\begin{array}{l}\text { O que faria o } \\
\text { participante não ir ou } \\
\text { não retornar a um hotel } \\
\text { fazenda }\end{array}$ & $\begin{array}{l}\text { "Falar que vai ser de um jeito e ser totalmente diferente, prometer que vai ser muito } \\
\text { bom e chegar lá e não ser nada daquilo que eles falaram" (Grupo 2). }\end{array}$ \\
\hline $\begin{array}{l}\text { O que faria uma } \\
\text { experiência se tornar } \\
\text { única }\end{array}$ & $\begin{array}{l}\text { "Se exceder as expectativas que a gente tem de um hotel fazenda" (Grupo 1). } \\
\text { "É se atender as expectativas, você realmente relaxar e voltar cheio de ânimo, de } \\
\text { vida, pra poder voltar pra correria depois, [...] com algumas surpresas, alguma } \\
\text { coisa que superasse um pouquinho as expectativas" / "Eu acho que não depende } \\
\text { muito do hotel se sua experiência vai ser única, depende da sua expectativa e da sua } \\
\text { experiência passada mesmo" / "Se sua expectativa estiver muito baixa e aí, mesmo } \\
\text { que o hotel não seja incrível, mas supere muito sua expectativa, pode se tornar uma } \\
\text { coisa meio única" / "Uma coisa inesperada que não estava nas suas expectativas, } \\
\text { que aconteceu e foi muito boa, e por isso marcou" (Grupo 4) }\end{array}$ \\
\hline $\begin{array}{l}\text { "Eu esperaria um lugar afastado, com muito verde e andar a cavalo, mas acho que } \\
\text { essa não é essa sensação. [...] é mais se sentir distante, assim, desse sufocamento } \\
\text { que a gente encontra na cidade. Essa é a sensação que eu esperaria" (Grupo 4). }\end{array}$ \\
\hline
\end{tabular}
Fonte: Elaborado pelos pesquisadores (2018)

Em geral, ao abordarem a satisfação, os grupos se concentraram no conceito de expectativa, congruente com Mowen e Minor (2003) e Kotler e Armstrong (2014), ilustrando diversos pontos em que a expectativa poderia, ou não, ser atingida, bem como relevando elementos que direcionariam à satisfação.

A expectativa foi entendida como um estado no qual a experiência de hospedagem é vista pelo hóspede antes da viagem, sendo a estadia considerada boa quando a percepção sobre ela foi perto daquilo que foi esperado. Também foi tratado o contexto em que a expectativa foi excedida, em que essa situação levaria a sensação de uma experiência única na hospedagem. Pelo outro lado, uma propaganda divulgada que fosse diferente e negativamente impactante poderia gerar uma frustração. Mostra-se, assim, que como posto por Lovelock e Wright (2003), Oliver (2014) e Kumaret al. (2013), o desempenho da firma, no sentido da confirmação da expectativa do consumidor, contribui para a satisfação do cliente.

\subsection{Cocriação}

Em geral, a compreensão que os respondentes têm de cocriação em hotéis fazenda é voltada ao feedback dado em caixas de sugestões, redes sociais e sites destinados a isso. Eles acreditam que uma vez acatadas, as sugestões auxiliaram e cocriaram uma nova realidade, uma novidade ou mudança no 
MARKETING DE RELACIONAMENTO EM

HOTÉIS FAZENDA: UM FRAMEWORK A PARTIR

DA EXPERIÊNCIA
Iury Teixeira de Sevilha Gosling

Daniel Carvalho de Rezende

Marlusa de Sevilha Gosling

Francis Marcean Resende Barros

Rauf Rodrigues Soares

local. Ainda assim, os participantes mencionaram que o feedback só seria dado caso os hotéis procurassem por eles. A maioria concordou que a inciativa para um elogio ou uma sugestão de melhoria raramente parte do usuário. Em muitos casos, quando fazem isso é no sentido de reclamação, mas não para prestar outro tipo de apoio à atividade: "Na hora que ele me perguntasse: "E aí, a estadia foi boa? Você tem alguma sugestão?" Eu falaria, mas, se não entrasse em contato, eu também não entraria" (Grupo 3). Nesse sentido, também se menciona:

Acho que através da participação, da disponibilidade em participar. [...] A própria interação com os funcionários para não causar climas ruins. Tratar bem os funcionários. [...] Acho que a partir dessa disponibilidade de integrar mesmo, tanto o ambiente quanto com as pessoas que estão lá. Eu acho que isso ajuda a fazer essa cocriação de um ambiente melhor de atividades melhores (Grupo 6).

Ainda que limitada, essa forma de cooperação está de acordo com Evans e Laskin (1994) e Yamashita e Gouvêa (2007), que destacam a importância de se tratar os feedbacks dos clientes para uma construção no marketing de relacionamento. Outra narrativa aponta a iniciativa de melhoria do aspecto do local como forma de cocriação: "Já íamos voltar quando vimos a entrada do hotel. Tinha um bambuzal na entrada, que tampava tudo. [...] Então meu pai sugeriu que retirasse um pouco para ficar mais visível e clareasse um pouco. Foi legal" (Grupo 3).

Foi abordado que o "[...]cliente influencia no serviço também, no sentido lateral com sua participação na experiência" (Grupo 1). A possibilidade de cocriação foi apontada também nas interações e envolvimento em atividades, como por exemplo, tirar leite da vaca, auxiliar a montar o equipamento em alguma atividade, preparar os alimentos, envolver-se em cursos de culinária, entre outros.

Outros pontos de vista enfatizam a confusão entre a oferta de atividades e a cocriação: "Um passeio a cavalo, isso não é cocriar. Isso é uma atividade que eles oferecem" (Grupo 5); e, em certo grau, o receio em relação a cocriação: "Eu não gosto de fazer atividades com desconhecido, no geral, então só se fosse agregar em alguma coisa para mim mesmo" (Grupo 1).

Foi notado, ainda, que os participantes mostraram que a finalidade de descanso pode ser conflitante com a cocriação, quando questionados sobre atividades de cocriação em hotéis fazenda: "Os monitores insistindo para o "cara” participar e ele lá quietinho no canto dele. E o outro lá, chamando toda hora". "[...] quer descansar, ficar só na piscina, quer pescar tranquilo, quer fazer qualquer outra coisa que não fazer uma hidroginástica na piscina" (Grupo 6).

Também foi mencionado que os principais indivíduos dispostos a cocriarem são as crianças, mais abertas e dispostas a novidades, a novas amizades e com mais vigor físico: "Eu lembro que as crianças participavam viu? Chamavam: "Ah Vem você". [...] Porque criança anima pra tudo" (Grupo $1)$. 
MARKETING DE RELACIONAMENTO EM

HOTÉIS FAZENDA: UM FRAMEWORK A PARTIR

DA EXPERIÊNCIA
Iury Teixeira de Sevilha Gosling Daniel Carvalho de Rezende Marlusa de Sevilha Gosling Francis Marcean Resende Barros Rauf Rodrigues Soares

\subsection{Framework teórico da experiência em hotéis fazenda}

Com base nessa análise, a Figura 2 ilustra o framework proposto em relação à experiência em hotéis fazenda, considerando os construtos analisados no conteúdo dos grupos focais.

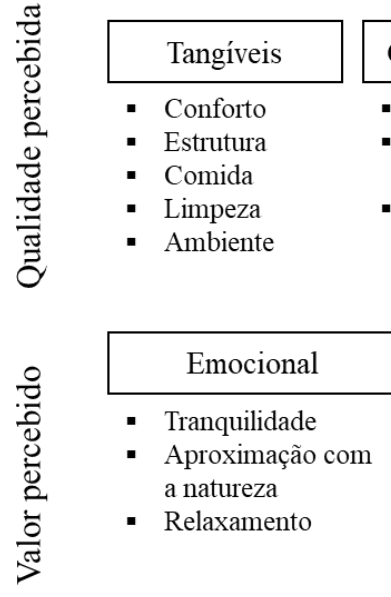

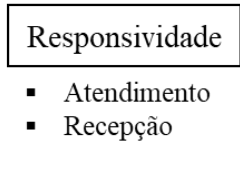

Soluções

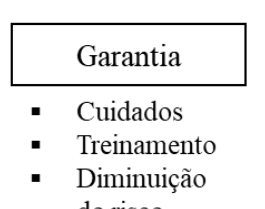
do risco

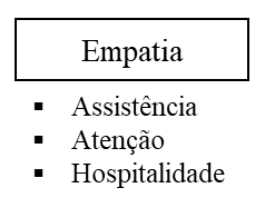

- Assistência

- Hospitalidade

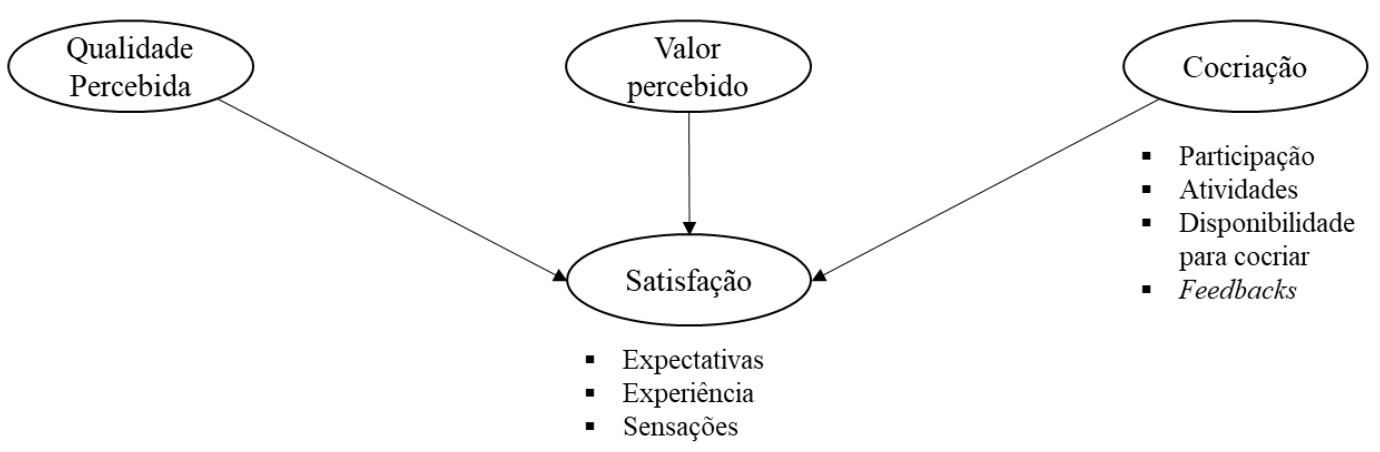

Figura 2. Framework proposto

Fonte: Elaborado pelos pesquisadores (2018)

Desse modo, a seção seguinte aborda as implicações do estudo, suas limitações e sugestões para pesquisas futuras.

\section{Considerações finais}

Com base nessa análise, compreende-se que o objetivo geral do artigo foi atingido, evidenciando e estruturando os construtos relacionados ao marketing de relacionamento no contexto investigado. 
MARKETING DE RELACIONAMENTO EM

HOTÉIS FAZENDA: UM FRAMEWORK A PARTIR

DA EXPERIÊNCIA
Iury Teixeira de Sevilha Gosling

Daniel Carvalho de Rezende

Marlusa de Sevilha Gosling

Francis Marcean Resende Barros Rauf Rodrigues Soares

Para a academia, o estudo contribui com uma releitura de modelos tradicionais no contexto de hotéis-fazenda, provendo uma estrutura teórica que considera a qualidade percebida, o valor percebido, a satisfação e a cocriação nessa atividade. A discussão sobre a cocriação, ainda que a prática aconteça de maneira tímida, amplia a discussão do Marketing de Relacionamento sob a perspectivas de interações mais relacionais entre as empresas e os clientes. Afinal, uma experiência positiva tende a aumentar a satisfação e a lealdade, expressa em intenção de revisitar e de recomendar. Nesse sentido, variáveis-chave para o Marketing de Relacionamento são abordadas.

O artigo também contribui com a gestão dos hotéis-fazenda, tendo como base a análise dos elementos observados e julgados como motivadores da ida ou da não ida aos hotéis. Recomenda-se que a prática de cocriação pode ser difundida para alcançar a percepção dos hóspedes e contribuir com a percepção da qualidade e da satisfação da experiência. No entanto, é importante analisar o segmento de clientes que está mais propenso à cocriação, pois a implantação deliberada das práticas de cocriação pode interferir negativamente na experiência de hóspedes que não estão dispostos a cocriar.

Como limitação, compreende-se que o framework, obtido dos resultados, é dado em estágio de proposição. Sendo assim, estudos futuros podem aprofundar os achados, ao replicar o roteiro em hotéis específicos, caracterizando estudos de caso múltiplos. Adicionalmente, em uma etapa posterior, para fins de generalização e tomada de decisão, poder-se-ia estender os achados com pesquisa quantitativa descritiva, coletando dados com os hóspedes de hotéis-fazenda, para aumentar a validade da proposta.

Estudos futuros também podem verificar fatores que levam a não aderência da cocriação, além do caráter simples de segmentação exposto neste trabalho. Dessa forma, é possível aprofundar a investigação da variável, ampliando a iniciativa desse artigo.

\section{Referências}

ACHROL, R.; KOTLER, P. Frontiers of marketing paradigm in the third millennium. Journal of the Academy of Marketing Science, v. 40, n.1, p. 35-52, 2012.

AMADO, F. A. M. City Branding: turismo, co-criação e qualidade de vida na cidade. Tese (Mestrado), Universidade Europeia, Lisboa, 2017.

ARAUJO, D. A. B.; JESUS, C. M. Cocriação de valor e a experiência do consumidor: revisão da literatura. EnANPAD, 2016.

BARAKAT, L. L.; LARA, J. E.; GOSLING, M. O surgimento da escola de pensamento do marketing de relacionamento e seus fundamentos. Pretexto, v. 12, n. 3, p. 29-46, 2011.

BARDIN, L. Análise de conteúdo. 3. reimp. Lisboa: Ediçoes, v. 70, 2011. 
MARKETING DE RELACIONAMENTO EM

HOTÉIS FAZENDA: UM FRAMEWORK A PARTIR

DA EXPERIÊNCIA
Iury Teixeira de Sevilha Gosling

Daniel Carvalho de Rezende

Marlusa de Sevilha Gosling

Francis Marcean Resende Barros Rauf Rodrigues Soares

BARRETO, I. F.; CRESCITELLI, E. Marketing de relacionamento: como implantar e avaliar resultados. São Paulo: Pearson Education do Brasil, 2013.

BERGAMO, F. V. M. O marketing de relacionamento revisitado: as relações comprador-vendedor no contexto da cibercultura. Tese (Doutorado), Universidade Federal da Bahia, Salvador, 2017.

BRASIL. Ministério do Turismo. Turismo rural: orientações básicas. / Ministério do Turismo, Secretaria Nacional de Políticas de Turismo, Departamento de Estruturação, Articulação e Ordenamento Turístico, Coordenação Geral de Segmentação. - 2.ed - Brasília: Ministério do Turismo, 2010.

BRASIL. Ministério do Turismo. Plano Nacional de Turismo - 2018-2022: "Mais emprego e renda para o Brasil". Disponível em: http://www.turismo.gov.br/images/mtur-pnt-web2.pdf. Acesso em: 28 out. 2018.

CARMAN, J. M. Consumer perceptions of service quality: an assessment of the SERVIQUAL dimensions. Journal of Retailing, v. 66, p. 33-35, 1990.

CHURCHILL, G. A.; PETER, J. P. Marketing: criando valor para os clientes. São Paulo: Saraiva, 2000.

CORBETTA, P. Social research: theory, methods and techniques. Sage, 2003.

CRUZ, T. S.; ANDRADE, M. A. M.; GOSLING, M. S.; GOSLING, I. T. S. O uso da rede social facebook para o marketing: o caso da Amicci Moda. Revista da Universidade Vale do Rio Verde, v. 15, n. 2, p.132-151, 2017.

CURY, C. R. J. Qualidade em educação. Nuances: Estudos sobre Educação, v. 17, n. 18, 2011.

D'ANGElO, A. C.; SCHNEIDER, H.; LARAN, J. A. Marketing de relacionamento junto a consumidores finais: um estudo exploratório com grandes empresas brasileiras. Revista de Administração Contemporânea, v. 10, n. 1, p. 73-93, 2006.

DONALDSON, B.; O'TOOLE T. Strategic market relationships: from strategy to implementation. England: John Wiley and Sons, 2007.

EGAN, J. Relationship marketing: exploring relational strategies in marketing. London: Pearson, 2011.

EIRIZ, V.; WILSON, D. Research in relationship marketing: antecedents, traditions and integration, European Journal of Marketing, v. 40, n. 3/4, p. 275-291, 2006.

EVANS, J. R.; LASKIN, R. L. The relationship marketing process: a conceptualization and application. Industrial marketing management, New York, v. 23, p. 439-452, 1994.

GIL, A. C. Métodos e técnicas de pesquisa social. 6. ed. Editora Atlas SA, 2008.

GONÇALVES, E. P. et al. Marketing de relacionamento para fidelizar clientes. Gestão Contemporânea, Vila Velha, v. 2, n. 1, p. 58-69, 2012. 
MARKETING DE RELACIONAMENTO EM

HOTÉIS FAZENDA: UM FRAMEWORK A PARTIR

DA EXPERIÊNCIA
Iury Teixeira de Sevilha Gosling

Daniel Carvalho de Rezende

Marlusa de Sevilha Gosling

Francis Marcean Resende Barros Rauf Rodrigues Soares

GORDON, I. Marketing de relacionamento: estratégias, técnicas e tecnologias para conquistar clientes e mantê-los para sempre. São Paulo: Futura, 1998.

GRONRÖOS, C. Service Management and Marketing: a customer relationship management approach, Hoboken: John Wiley \& Sons, 2000.

GUELBERT, T. F. Estratégias de Marketing para Agroindústrias Familiares. Tese (Doutorado), Universidade Federal de Santa Catarina, Florianópolis, 2014.

GUMMESSON, E. Marketing de relacionamento total. Porto Alegre: Bookman, 2010.

HEITMANN, M.; LEHMANN, D.; HERRMANN, A. Choice goal attainment and decision and consumption satisfaction. Journal of Marketing Research, v. 44, n. 2, p. 234-250, 2007.

HIGUCHI, A. K. Cocriação de valor e mudança comportamental voluntária para o uso de preservativo: contribuições da lógica dominada por serviço ao marketing social. Tese (Doutorado), Universidade Federal de Minas Gerais, Belo Horizonte, 2017.

HOLLENSEN, S. Marketing Management: a relationship approach. New York: Financial Times/ Prentice Hall, 2003.

HUNT, S. D.; ARNETT, D. B.; MADHAVARAM, S. The explanatory foundations of relationship marketing theory. The Journal of Business \& Industrial Marketing, v. 21, p. 72-87, 2006.

KOTLER, P.; ARMSTRONG, G. Princípios de marketing. São Paulo: Pearson, 2014.

KOTLER, P.; KELLER, R. Administração de Marketing. São Paulo: Prentice Hall, 2006.

KUMAR, V. Introduction: is customer satisfaction (ir)relevant as a metric? Journal of Marketing, v. 80, p. 108-109, 2016.

KUMAR, V.; DALLA POZZA, I.; GANESH, J. Revisiting the satisfaction-loyalty relationship: empirical generalizations and directions for future research. Journal of Retailing, v. 89, n. 3, p. 246$262,2013$.

LARENTIS, F.; ANTONELlO, C. S.; SLONGO, L. A. Cultura organizacional e marketing de relacionamento: uma perspectiva interorganizacional. Revista Brasileira de Gestão de Negócios, v. 20, n. 1 , p. 37-56, 2018.

LOURES, C. A. S. Razões para a ocorrência dos gaps de gestão da qualidade de serviço: estudo de caso numa organização de transporte metroviário. Tese (Doutorado), Universidade de São Paulo, São Paulo, 2009.

LOVELOCK, C.; WRIGHT, L. Serviços, marketing e gestão. São Paulo: Saraiva, 2003.

MADRUGA, R. Guia de implementação de Marketing de Relacionamento e CRM. São Paulo: Atlas, 2010.

MALHOTRA, N. K. Pesquisa de marketing: uma orientação aplicada. Bookman Editora, 2012. 
MARKETING DE RELACIONAMENTO EM

HOTÉIS FAZENDA: UM FRAMEWORK A PARTIR

DA EXPERIÊNCIA
Iury Teixeira de Sevilha Gosling

Daniel Carvalho de Rezende

Marlusa de Sevilha Gosling

Francis Marcean Resende Barros Rauf Rodrigues Soares

MEDEIROS, N. C.; CAS, E. A.; MEDEIROS, F. S. B. Marketing de relacionamento: o caso de uma concessionária de veículos comerciais. Desafio Online, Campo Grande, v. 1, n. 1, 2016.

MELO, F. M.; MUNIZ, E. C. L. Application of the servqual model in the quality analysis of accounting services. Brazilian Journal of Production Engineering, v. 3, n. 2, p. 01-17, 2017.

MIQUEL-ROMERO, M. J.; GINER, M. C.; SÁNCHEZ, C. A. Relationship marketing management: its importance in private label extension. Journal of Business Research, v. 67, n. 5, p. 667-672, 2014.

MORGAN, R.; HUNT, S. The commitment-trust theory of relationship marketing. Journal of Marketing, v. 58, p. 20-38, 1994.

MORGAN, R. Relationship marketing and marketing strategy. InSHETH, J.; PARVATIYAR, A. Handbook of Relationship Marketing. (Eds.), p. 481-504, 2000.

MOURA, A. C.; GODINHO, L. A. C.; GOSLING, M.; MARTINS, J. F. Marketing de relacionamento via redes sociais: uma análise de sua aplicação. Revista Eletrônica de Administração, v. 13, n. 2, 2014.

MOWEN, J. C.; MINOR, M. S. Comportamento do consumidor. São Paulo: Prentice Hall, 2003.

NARANG, R. How do management students perceive the quality of education in public institutions? QualityAssurance in Education, v. 20, n. 4, p. 357-371, 2012.

NEGHINA, C.; CANIËLS, M. C. J.; BLOEMER, J. M. M.; BIRGELEN, M. J. H. Value cocreation in service interactions: dimensions and antecedents. Marketing Theory, v. 15, n. 2, p. 221-242, 2015.

NETO, M. R. A.; MOURA, A. I. Construção e teste de um modelo teórico de marketing de relacionamento para o setor de educação. EnANPAD, 2004.

OLIVER, R. L. Satisfaction: a behavioral perspective on the consumer. New York: Routledge, 2014.

PARASURAMAN, A.; ZEITHAML V. A.; BERRY, L. Servqual: A multiple-item scale for measuring consumer perceptions of service quality. Journal of Retailing, v. 64, n. 1, p. 12-40, 1988.

PARVATIYAR, A.; SHETH, J. N. Customer relationship management: emerging practice, process and discipline. Journal of Economic and Social Research, v. 3, n. 2, p. 1-34, 2001.

PAYNE, A. Handbook of CRM: achieving excellence in customer management. Oxford: Elservier, 2005.

PAYNE, A.; FROW, P. Relationship marketing: Looking backwards towards the future. Journal of Services Marketing, v. 31, n. 1, p. 11-15, 2017.

RAMASWAMY, V.; COUTINHO, A. Plataforma-cocriação-desenvolvimento. HSM Management, Barueri, v. 88, p. 50-58, 2011.

RAMASWAMY, V.; GOUILLART, F. A empresa cocriativa - Por que envolver stakeholders no processo de criação de valor gera mais benefícios para todos. Rio de Janeiro: Elsevier, 2010. 
MARKETING DE RELACIONAMENTO EM

HOTÉIS FAZENDA: UM FRAMEWORK A PARTIR

DA EXPERIÊNCIA
Iury Teixeira de Sevilha Gosling

Daniel Carvalho de Rezende

Marlusa de Sevilha Gosling

Francis Marcean Resende Barros Rauf Rodrigues Soares

RAMASWAMY, V.; OZCAN, K. The co-creation paradigm. Stanford: Stanford University Press, 2014.

ROQUE, A. M.; VIVAN, A. M. O Turismo no espaço rural: uma estratégia para a nova gestão rural brasileira. Organizações Rurais \& Agroindustriais, v. 1, n. 1, 2011.

ROSALEM, V. Análise das percepções dos principais atores da cadeia produtiva da saúde sobre a qualidade dos serviços prestados por hospitais no Estado de Goiás-BR. Tese (Doutorado), Fundação Getúlio Vargas, São Paulo, 2013.

SALVADO, J. O. M. G. Cocriação de valor na distribuição turística. Tese (Doutorado), Universidade de Aveiro, Aveiro, 2013.

SCARTON, L. M. Cocriação de valor em cadeias curtas de abastecimento alimentar: estudos de caso no Rio Grande do Sul. Tese (Doutorado), Universidade Federal do Rio Grande do Sul, Porto Alegre, 2016.

SCHEER, L. K.; MIAO, C. F.; PALMATIER, R. W. Dependence and interdependence in marketing relationships: meta-analytic insights. Journal of the Academy of Marketing Science, v. 43, n. 6, p. 694-712, 2015.

SHETH, J. N.; PARVATIYAR, A.; SINHA, M. The conceptual foundations of relationship marketing: review and synthesis. Economy Sociology The European Electronic Newsletter, v. 13, n. 3, p. 4-26, 2012.

SOLOMON, M. R. O comportamento do consumidor: comprando, possuindo e sendo. Porto Alegre: Bookman, 2016.

SWEENEY, J.; SOUTAR, G. Consumer perceived value: the development of a multiple item scale. Journal of retailing, v. 77, n. 2, p. 203-220, 2001.

TRIGO, I. L. Marketing de relacionamento e o papel da empatia na retenção de clientes. Tese (Doutorado), Pontifícia Universidade Católica de São Paulo, São Paulo, 2017.

VALÉRIO, F. R. Práticas de marketing de relacionamento entre fabricantes e distribuidores de defensivos agrícolas. Dissertação (Mestrado), Universidade de São Paulo, Ribeirão Preto, 2015.

VARGO, L.; LUSCH, F. Evolving to a new dominant logic for marketing. Journal of Marketing, v. 68 , p. 1-17, 2004.

VICENTE, E. C. O planejamento de marketing aplicado ao pequeno varejo: panificadora e confeitaria sonhos de brotas. Monografia (Pós-Graduação), Universidade Federal do Paraná, Curitiba, 2015.

WANG, J. J.; ZHANG, C. The impact of value congruence on marketing channel relationship. Industrial Marketing Management, v. 62, p. 118-127, 2017.

WORLD TRAVEL \& TOURISM COUNCIL - WTTC. Travel \& tourism economic impact 2017. Brazil. Março, 2017. 
MARKETING DE RELACIONAMENTO EM

HOTÉIS FAZENDA: UM FRAMEWORK A PARTIR

DA EXPERIÊNCIA
Iury Teixeira de Sevilha Gosling

Daniel Carvalho de Rezende

Marlusa de Sevilha Gosling

Francis Marcean Resende Barros Rauf Rodrigues Soares

WU, W.; TSAI, C.; FU, C. The Relationships among Internal Marketing, Job Satisfaction, Relationship Marketing, Customer Orientation, and Organizational Performance: An Empirical Study of TFT-LCD Companies in Taiwan. Human Factors and Ergonomics in Manufacturing \& Service Industries, v. 23, n. 5, p. 436-449, 2013.

XAVIER JUNIOR, C. E. R. Percepção de valor em uma oferta: o papel dos valores dos consumidores. Dissertação (Mestrado), Universidade Federal de Pernambuco, Recife, 2006.

YAMASHITA, S. S.; GOUVÊA, M. A. Marketing de relacionamento: importância e implicações no mercado consumidor. Revista de Administração Mackenzie, São Paulo, v. 8, n. 4, p.103-124, 2007.

ZEITHAML, V. A.; BITNER, M. J.; GREMLER, D. D. Marketing de serviços: a empresa com foco no cliente. Bookman: Porto Alegre, 2014. 